\title{
AS DIFERENÇAS NAS AÇÕES DO PROJETO DE SUSTENTABILIDADE DAS COMUNIDADES INDÍGENAS (ITAIPU) E DO PROJETO GATI NA TERRA INDÍGENA DO OCO'Y - PR
}

\author{
ROBERTO DOS ANJOS DIAS ${ }^{1}$ \\ UNIOESTE
}

NARDEL LUIZ SOARES SILVA ${ }^{2}$

UNIOESTE

\begin{abstract}
RESUMO: A Terra Indígena Oco'y, localizada no município São Miguel do Iguaçu - PR, é um pequeno território com alta densidade demográfica e condições ambientais, sociais e econômicas frágeis. Foi selecionado, juntamente a outras 32 Terras Indígenas no país, para ser local de implementação do Projeto de Gestão Ambiental de Terras Indígenas (GATI). Ao mesmo tempo, já estava sendo realizado, há 10 anos, outro projeto de desenvolvimento sustentável incentivado pela empresa Itaipu Binacional. Através de análise crítica e comparação entre esses dois projetos, que possuem objetivos semelhantes, conclui-se que a forma de condução da Itaipu visa resultados imediatos, suprindo as necessidades indígenas, no entanto sem grande participação da comunidade nas decisões e sem contribuir com a autonomia indígena. Percebe-se que as ações realizadas não são sustentáveis e o termo "sustentabilidade" é apenas recurso de marketing. Por outro lado, o GATI, realizado a partir das diretrizes da Política Nacional de Gestão Territorial e Ambiental de Terras Indígenas, foca na satisfação das necessidades presentes e futuras, promovendo ações que respeitam a autonomia e participação indígenas, respeitando as características ambientais e culturais do território.
\end{abstract}

PALAVRAS-CHAVE: gestão ambiental e territorial; Itaipu; Avá-Guarani.

ABSTRACT: Oco'y Indigenous Land, in the city of São Miguel do Iguaçu - PR, is a small territory with high population density and frail social, economic and environmental. Oco'y has been selected, along with other 32 indigenous lands in the country, to be the place of implementation of the Indigenous Lands Environmental Management Project (GATI). At the same time, another sustainable development project was already being held for 10 years, promoted by Itaipu Binacional Company. Through critical analysis and comparison of these two projects that have similar goals, we conclude that the way Itaipu conducts the project seeks immediate results,

\footnotetext{
${ }^{1}$ Graduado em Geografia pela Universidade Estadual do Oeste do Paraná - UNIOESTE, mestrando em Desenvolvimento Rural Sustentável - UNIOESTE. Membro do Grupo de Pesquisa: Meio Ambiente: Sociedades Tradicionais e Sociedade Hegemônica - PUC/PR. E-mail: rd_dias@yahoo.com.br .

${ }^{2}$ Graduado em Agronomia (UFSM), Mestrado em Agroecossistemas (UFSC), Doutorado em Agronomia (UEM), coordenador do Programa de Pós Graduação em Desenvolvimento Rural Sustentável UNIOESTE. E-mail: nardel.silva@unioeste.br .
} 
meeting the indigenous needs, though without much community participation in decisions and without contributing to indigenous autonomy. It is possible to notice that the actions taken are not sustainable and the term "sustainability" is used just for marketing appeal. On the other hand, GATI, conducted by the guidelines of the National Policy on Territory and Environmental Management of Indigenous Lands, focuses on meeting the current and future needs, promotes actions that respect indigenous autonomy and participation, respecting environmental and cultural characteristics of the territory.

KEYWORDS: environmntal and territorial management; Itaipu; Avá-Guarani.

\section{Introdução}

Atualmente encontra-se em fase de execução o Projeto de Gestão Ambiental e Territorial de Terras Indígenas (GATI), com previsão para ser realizado em 32 terras indígenas no Brasil. O GATI é a práxis da Política Nacional de Gestão Territorial e Ambiental de Terras Indígenas (PNGATI) tanto no campo teórico-metodológico, com a construção de novas abordagens e ferramentas de gestão, como também na prática, através de reuniões entre órgãos públicos e indígenas estabelecendo planos de ação e a organização de oficinas e cursos para a formação de profissionais.

O Projeto possui como norte de suas ações o uso sustentável dos recursos, de forma que isto implique na possibilidade de reprodução física e cultural dos povos indígenas e de suas futuras gerações. Dessa forma, o Projeto GATI tem por objetivo fortalecer as práticas indígenas tradicionais, o uso sustentável, a conservação dos recursos naturais e a inclusão social dos povos indígenas de forma que também auxilie na conservação do bioma local (O QUE É O PROJETO GATI?, 2015).

Dentre as terras indígenas selecionadas para o Projeto GATI está a Terra Indígena Oco'y, no município de São Miguel de Iguaçu - PR, ocupada por indígenas do subgrupo Avá-Guarani. A Terra Indígena localiza-se às margens do Lago de Itaipu, sobreposta à Área de Preservação Permanente do Lago, e apresenta diversas fragilidades ambientais, sociais e econômicas tanto do ponto de vista não indígena quanto do indígena. 
Outra iniciativa de desenvolvimento sustentável na TI Oco'y vem sendo realizada há 12 anos pelo Projeto Sustentabilidade das Comunidades Indígenas, encabeçado pela Itaipu Binacional e demais parcerias locais e regionais.

Dentre os desafios da implantação de projetos de sustentabilidade na TI Oco'y estão o excesso de população, um total de 646 pessoas (IBGE, 2012) e o pequeno território, produção incipiente para a alimentação da comunidade e direitos e proibições que se contradizem. Dessa forma, necessita-se de uma estratégia de gestão construída de dentro da comunidade em articulação com as instituições envolvidas no projeto para que sejam superadas essas situações que inviabilizam a sustentabilidade da comunidade indígena.

O presente trabalho foi realizado a partir de uma perspectiva crítica baseada nas informações disponíveis em bibliografia sobre os projetos de sustentabilidade realizados e projetados para a Terra Indígena do Oco'y, entre outras. Também foram consultados sites institucionais, uma vez que o tema é recente e as informações são escassas.

A novidade do tema é, porém, algo positivo, devido à oportunidade de acompanhar as ações que estão sendo realizadas, como também a possibilidade de analisar a relação entre a prática e a teoria. Ademais, há certa relevância pelo ineditismo do tema "gestão territorial em terras indígenas no Sul do país", ainda que se torne um desafio devido às poucas fontes disponíveis.

Este artigo realiza uma investigação sobre as experiências de gestão de recursos naturais e sustentabilidade, incentivadas pela Itaipu Binacional e a partir da Política Nacional de Gestão Ambiental e Territorial de Terras Indígenas, resultando em avaliações com sugestões de caminhos a serem seguidos.

\section{Discussão}

A Terra Indígena do Oco'y, na região oeste do Paraná, foi demarcada em 1982 como compensação pelos territórios que seriam alagados com a construção do Lago de Itaipu. Entretanto, a demarcação 
abrigou apenas um número pequeno de famílias indígenas, sendo necessário, anos depois, assentar outras famílias em outra terra indígena. Tal atitude ainda não foi suficiente e atualmente o território não possui espaço para a reprodução física e cultural dos indivíduos (CARVALHO, 2013).

A Terra Indígena Oco'y é ocupada por indígenas guarani pertencentes ao subgrupo Avá-Guarani, conhecidos também como Ñandéva, Chiripá, Ava-Katu-Ete. Todavia, havendo diversos registros bibliográficos que os registram como Avá-Guarani no Oeste Paranaense (DEPRÁ, 2006) e, sobretudo por se auto identificarem desta forma, optase, neste trabalho, por esta nomenclatura.

Os Avá-Guarani apresentam características sociais distintas da sociedade envolvente, principalmente em sua relação intrínseca entre o meio ambiente e sua reprodução física e cultural (BRIGHENTI, 2005), realizada com a condição da preservação ambiental, entendendo os recursos naturais como elementos sagrados que devem ser manejados com sabedoria, o que se constitui "em uma ética de interação não abusiva com a natureza” (ALBERNAZ, 2007, p.151).

Devido a estas características, há uma demanda de se aperfeiçoar o uso dos recursos do território, aproveitando da melhor forma o pouco espaço disponível para a pesca, o cultivo de matéria prima para artesanato, alimentos, plantas tradicionais e, principalmente, para a agricultura, característica de maior relevância para esta sociedade (RIBEIRO, 2006), como também outras atividades possíveis de serem conciliadas com o modo de ser guarani, tal como a criação de animais, apicultura e agroflorestas.

Embora existam qualidades fundamentais que incentivem a implantação de projetos de desenvolvimento sustentável na comunidade Oco'y, como a organização e a demanda da comunidade por sustentabilidade, um território limitado e com certa autonomia de gestão, bem como órgãos e instituições que têm interesse no desenvolvimento de tais projetos, também ocorrem diversos outros fatores que se mostram urgentes e impactam diretamente em projetos para a sustentabilidade da comunidade.

O mais relevante é a questão fundiária e a necessidade de ampliar os limites do território, principalmente por se encontrarem localizados 
em uma Área de Preservação Permanente (APP) às margens do Rio Paraná, local em que não deveria haver ocupação humana, como também a falta de terra para o manejo, a dispersão de agrotóxicos em propriedades vizinhas que atingem a Tl, entre outros problemas jurídicos ambientais. (CARVALHO, 2013).

A questão fundiária do TI Oco'y nasce juntamente com a sua localização, pois está situada numa estreita faixa, em formato de "V", constituindo-se em um trecho de Área de Preservação Permanente (margem do Lago de Itaipu). Segundo Carvalho (2013), a margem brasileira do Lago deve ter APP 210 metros e, em toda ela, não é permitido que viva nenhuma população; a exceção é somente no trecho que condiz com a TI Oco'y, pois ali a APP tem 100 metros e, também, vivem os indígenas. De qualquer forma, Carvalho (2013) ressalta que tal extensão ainda não corresponderia ao previsto pelo Código Florestal vigente durante o período de demarcação.

Com a alteração para o novo Código Florestal (12.651/12), a nova lei determinou que as APP de reservatórios destinados à geração de energia, que foram autorizados "anteriormente à Medida Provisória no 2.166-67, de 24 de agosto de 2001, a faixa da Área de Preservação Permanente [seriam] a distância entre o nível máximo operativo normal e a cota máxima maximorum", o que seria, portanto, uma diminuição quase que total da APP.

Para evitar possíveis equívocos, Caribé (2013) adverte quanto à interpretação literal deste artigo, que conflitaria com a estrutura constitucional atual. Assim, devem ser considerados os atos legais já consolidados, aliados à atual legislação, devendo ser respeitadas as decisões tomadas no processo pelo órgão ambiental responsável. Todavia, o novo Código Florestal indica a necessidade do licenciamento ambiental para determinar a Área de Preservação Permanente, porém a Itaipu nunca realizou nenhum tipo de licenciamento ambiental para a sua instalação que possa servir de base (CARVALHO, 2013).

Como os indígenas foram assentados neste local, acabou por se configurar também como Terra Indígena, garantindo, por meio do Artigo 231, §2 da Constituição Federal, "o usufruto exclusivo das riquezas do solo, dos rios e dos lagos nelas existentes". Ou seja, até então havia uma sobreposição de dois limites jurídicos: o primeiro que considerava o local 
como um território com o intuito específico de conservação ambiental, impedindo a utilização dos recursos naturais por parte dos indígenas, e um segundo que garante a presença de uma população indígena e o uso de todos os recursos naturais ali existentes.

Com o advento do novo Código, é possível criar alternativas de utilizar os recursos conciliando as duas determinações jurídicas. Uma vez que a nova legislação contribui, de certa forma, para colocar panos quentes no impasse, pois prevê, através do Art. 9, o acesso à APP para atividades de baixo impacto ambiental, o que permite, com algumas ressalvas, a construção de moradias, cercas, atividades de manejo florestal, coleta de produtos madeireiros, produção de mudas e plantio de espécies nativas, entre outras atividades. Dessa forma, abafa o conflito entre as leis ambientais e indígenas de um modo em que se beneficiaram os indígenas, que podem procurar meios de elaborarem atividades de baixo impacto ambiental, e, devido aos interesses em realizar práticas sustentáveis na Terra Indígena, podem contribuir com a conservação da mata ciliar.

Atualmente, a Terra Indígena conta com aproximadamente 238 metros de largura em cada braço do seu formato em "V", constituindo-se em um ínfimo território para uma população numerosa e que tende a aumentar. Contribui para a redução do seu território a ação de agricultores vizinhos, que invadem porções da TI (ALBERNAZ, 2007; CARVALHO, 2013) e a inevitável ocupação com infraestrutura, o que impossibilita o manejo agrícola itinerante tradicionalmente realizado pelos indígenas. Graças à área reduzida é necessário que se cultivem as roças continuamente nos mesmos locais, contribuindo para o desgaste do solo e, consequentemente, gerando baixa produtividade das culturas agrícolas (CARVALHO, 2013, p. 174).

Adriana Albernaz (2007) afirma:

A situação é grave porque o tamanho da área de Oco'y que está disponibilizada para a agricultura impede que as pessoas que vivem ali se sustentem e se organizarem de acordo com suas formas tradicionais. Portanto, devido ao pequeno tamanho da área, os Ava-Guarani se deparam com a impossibilidade de plantarem em uma quantidade de terra suficiente para a produção agrícola, como também de terem um terreno com mata grande o suficiente para abrigar uma flora e fauna que propicie 
animais, remédios, madeira (para o fogo e para as construções tradicionais) e alimentos (ALBERNAZ, 2007, p. 151).

Devido ao reduzido território, a área florestada foi ocupada e, assim, os poucos recursos de flora foram se extinguindo, o que impacta na coleta de remédios, alimentos e matéria-prima para artesanatos, pequena fonte de renda de algumas famílias, e, com a presença indígena, nenhuma caça permaneceu (CARVALHO, 2013).

A pesca, segundo Carvalho (2013), é, por sua vez, impactada pelo controle das comportas da Usina de Itaipu, que afeta os peixes através da variação do nível de água, como também é atingida pelos agrotóxicos das propriedades vizinhas, em função de ser uma área em declive de uma microbacia.

Diante deste contexto, acredita-se que os indígenas necessitam de ações voltadas ao desenvolvimento sustentável de modo que consigam um aproveitamento dos recursos naturais em harmonia entre as dimensões ambiental, econômica, ecológica, social e cultural, como proposto por Sachs (2002).

O presente trabalho compartilha também das afirmações de Leonardo Boff (2015) sobre desenvolvimento sustentável. O autor afirma que isto pode ser entendido como a "ampliação das oportunidades de modelar a vida e definir-Ihe um destino" (BOFF, 2015, p. 136). Assim, o desenvolvimento é visto como a construção da autonomia. E compreende que a "sustentabilidade é um modo de ser e de viver que exige alinhar as práticas humanas às potencialidades limitadas de cada bioma e às necessidades das presentes e futuras gerações" (BOFF, 2015, p. 16).

Assim, percebe-se ser necessário produzir meios para que esta comunidade se desenvolva de maneira sustentável, extraindo recursos do território e utilizando-os da maneira mais próxima do seu modo tradicional, sem comprometer a possibilidade das futuras gerações satisfazerem suas necessidades. Compreende-se que o desenvolvimento sustentável deve contribuir para a autonomia dos indivíduos, para que estes possam continuar a definir seu futuro sem a necessidade de ações externas. 


\section{Projeto Sustentabilidade das Comunidades Indígenas, realizado pela Itaipu Binacional}

Algumas atividades já estavam sendo realizadas na TI Oco'y visando o desenvolvimento sustentável, com o intuito de modificar a sua realidade. Buscando a produção para suprir as necessidades alimentares e o fortalecimento da infraestrutura das aldeias, desde 2003 a Itaipu desenvolve o "Projeto Sustentabilidade das Comunidades Indígenas", que integra o "Programa Cultivando Água Boa da Itaipu Binacional", que também implantou tanques-rede para a criação de peixes na Terra Indígena através do "Programa Mais Peixes em Nossas Águas" (JORNAL, 2013).

As ações prosseguem e, segundo o Relatório Anual (2014), foram repassadas cestas básicas e alimentos, frutos de convênios e doações; assistência técnica; doação de mudas, sementes e matéria orgânica. $O$ Relatório ainda informa que, em 2014, houve o preparo de 48 hectares de solo com máquina agrícola.

É interessante ressaltar o que Carvalho (2013) relata: em 2003, houve um processo judicial que a Fundação Nacional do Índio (Funai), o Município de São Miguel do Iguaçu e a Itaipu sofreram por parte do Instituto Ambiental do Paraná (IAP) por realizar o preparo do solo em um total 80 hectares da Terra Indígena com máquina agrícola. Nesta situação de impasse, segundo a autora, as ações foram ambientalmente inadequadas e antropologicamente incorretas, uma vez que ao passar o maquinário eliminou-se parte da já pouca biodiversidade, deixando o solo exposto - o que pode deixá-lo infértil no futuro, visto que os AváGuarani do Oco'y não possuem tecnologias e nem meios financeiros de utilizar tecnologias externas para corrigir o solo, muito menos em área tão extensa.

Este método de manejo do solo desconsidera características antropológicas de cultivo que seriam mais adequadas, pois a agricultura tradicional guarani é baseada no cultivo de uso e pousio, agricultura itinerante, isto é: utiliza-se uma área para plantação durante determinado tempo; depois, ela é substituída por outra, deixando a primeira descansar e recuperar suas qualidades produtivas (CARVALHO, 2013; BRIGHENTI, 2005). 
Como afirma Brighenti (2005)

Importante observar que os Guarani praticam um intenso manejo ambiental, pois com o tempo de descanso da terra e sua regeneração e ao longo das trilhas nas matas secundárias, crescem as plantas utilizadas na coleta, atraindo animais e ampliando a fomentando a multiplicidade de espécies (BRIGHENTI, 2005, p. 44).

Embora seja o cultivo mais adequado ambientalmente, como já foi dito, é impossível de ser realizado na Terra Indígena devido à sua área. Entretanto, há alternativas que melhor se adequam às especificidades da cultura indígena e ao cuidado ao meio ambiente, como, por exemplo, o modo de cultivo agroecológico que abordaremos adiante. Ademais, através do manejo convencional, com maquinário agrícola e insumos, ataram a comunidade à dependência de apoio externo para realizar a correção do solo.

Em contrapartida, a socióloga da Itaipu afirmou que, sem este procedimento, os indígenas não teriam como se alimentar (CARVALHO, 2013). Entretanto, como estava claro,

a falta de condições para que os Guarani realizem sua subsistência, redundando "na falta de alimentos", não estaria relacionada ao tipo de tecnologia utilizada pelos índios - que continuamos a afirmar, é a mais adequada ao ambiente, mas sim à falta absoluta de espaço físico na Terra Indígena, para prover as necessidades de subsistência dos Guarani (CARVALHO, 2013, p. 456).

Ao não se ater na necessidade de rever os limites do território, a socióloga e o antropólogo representantes da Itaipu no processo não estariam "considerando o interesse em assegurar as condições de subsistência à comunidade indígena" (CARVALHO, 2013, p. 458), como também apenas consideram o modo de cultivo convencional como o único possível de ser realizado.

Albernaz (2007) relata que, devido ao frágil contexto territorial, os indígenas de certo modo aceitam as inovações vindas da sociedade não indígena, como a utilização de maquinário agrícola, entre outras; contudo, se mantêm críticos à sociedade dos "brancos" (não indígenas) e, através de discursos e da atuação das lideranças, buscam reconstruir o 
sistema tradicional indígena, produzindo atos de reinvindicação por mais terras com as características adequadas para sua sobrevivência. ${ }^{3}$

Para Albernaz (2007):

É possível afirmar que neste equilíbrio delicado entre aceitação de inovações tecnológicas e de instituições da sociedade ocidental e o resgate de relações tradicionais, a utilização de maquinaria agrícola representa da melhor forma o primeiro termo, enquanto a reatualização da caça e da coleta, mediante a presença da mata de uma forma mais intensa, representam bem o segundo (ALBERNAZ, 2007, p. 155).

Embora aceitem algumas interferências externas, permanecem críticos e afirmam que seu modo de manejo tradicional está sendo esquecido pelas novas gerações, pois precisam se adaptar ao sistema proporcionado pela Itaipu (CARVALHO, 2013, p. 458).

Percebe-se que os Avá-Guarani do Oco'y aceitam as novas condições pois são os meios possíveis de manterem a sobrevivência, mas não perdem de vista a sociedade ideal, uma concepção que certamente lembra o popular mito guarani da Terra sem Mal e do bem-viver4.

Com base na informação e nas fotos disponíveis no Relatório Anual (2014), constata-se que a Itaipu continua a estimular a agricultura dentro de uma lógica que não leva em conta os aspectos socioculturais indígenas. Uma vez que estes têm o desejo de praticar e resgatar princípios da sua a agricultura tradicional, devem ser buscados meios de estimular este modo de cultivo.

Leonardo Boff (2015) afirma que o propósito do desenvolvimento é estimular as potencialidades humanas e para isso deve-se contar com as tecnologias, as ciências e os modos de produção, os quais devem estar compromissados com a vida de todos. Embora o modo com que vem sendo feito o cultivo agrícola na TI tenha dado resultados na produção de alimentos, acredita-se que, do ponto de vista da sustentabilidade, ele ainda pode ser melhorado, através da aplicação de outras formas de tecnologias e técnicas mais sustentáveis.

\footnotetext{
${ }^{3}$ Suas mobilizações resultaram na conquista de 1700 hectares no município de Diamante do Oeste, onde hoje é a Tekohá Anhetete e para onde se mudaram 40 famílias da TI Oco’y em 1997.

${ }^{4}$ C.f. Nimuendaju (1987).
} 
Mesmo que realizadas com as melhores das intenções, as atividades descoladas da realidade e da cultura indígena trazem grandes impactos na reprodução cultural indígena. Assim, pode-se considerar que tal medida não compatibiliza com o desenvolvimento sustentável. O estímulo de uma agricultura não tradicional, além de ser insustentável, demonstra a não homogeneidade do "Projeto Sustentabilidade das Comunidades Indígenas“, pois ignora que são indissociáveis as práticas cotidianas da vida indígena como parte da cultura, e não como algo a ser recorrido quando necessário.

Há ainda ressalvas sobre os resultados do "Programa Mais Peixes em Nossas Águas". Segundo Orsi (2011), as atividades até então não estariam atendendo os objetivos dos indígenas de gerar alimento para a comunidade, pois não haveria uma regularidade na entrega dos peixes e o consumo foi muito abaixo dos padrões recomendados pela Organização Mundial da Saúde. Para a autora, há ainda um desinteresse da comunidade no projeto, pois estes consideram obrigação da Itaipu em fornecer o peixe, uma vez que foi esta instituição que os desalojou.

Orsi (2011) considera necessária a maior participação da comunidade e não só a participação da liderança nos processos decisivos. Além de importante, a participação democrática da comunidade e a consulta prévia a todas as ações realizadas na terra indígena é um direito reconhecido pela Convenção $n^{\circ} 169$ da Organização Internacional do Trabalho (OIT), da qual o Brasil é signatário, e a Declaração Internacional dos Povos Indígenas da Organização das Nações Unidas (ONU).

A participação democrática da comunidade reforça as relações como os laços de confiança e reciprocidade dos membros da comunidade, pelo sentimento de cooperativismo, e, tornando o grupo mais unido em torno de um objetivo final, proporciona que o projeto tenha continuidade a partir da gestão endógena.

Sobre a participação social no desenvolvimento, Buarque (1999) afirma:

A integração participativa do cidadão na vida política e social é um fator importante também para a sustentação política das políticas, assegurando a efetividade e a continuidade das decisões. Por outro lado, a participação é um bem de grande valor para a qualidade de vida, representando objetivo adicional a ser perseguido pelo 
desenvolvimento sustentável, pelo que representa em realização humana e socialização (BUARQUE, 1999, p. 33).

É relevante notar como a participação da comunidade poderia implicar em outros rumos para o projeto, pois, como dito anteriormente, a população deve estar envolvida desde a formulação dos projetos, determinando como realizar as atividades e se comprometendo na sua realização até a distribuição dos resultados.

Isto é, as ações devem ser pensadas também com o objetivo de reforçar e estimular o capital social, entendido como "confiança social, normas de reciprocidade, redes de engajamento cívico e, finalmente, de uma democracia saudável e vital, sendo a formação do estoque de capital social resultado de um longo processo histórico" (FREY, 2003, p. 176). Esta noção deve estar inserida em um projeto de desenvolvimento sustentável, assim as ações devem promover a capacitação e profissionalização de forma com que os indígenas possam dar continuidade ao projeto independente da presença de instituições externas, o que necessariamente implica em as ações serem constituídas de processos acessíveis aos indígenas e próximos da realidade local.

Ademais, a participação social no caso da TI Oco'y é propiciada pela escala territorial reduzida e bem definida, o que, para Buarque (1999), facilita a descentralização das decisões das instituições e "fortalece o poder local e amplia as oportunidades do cidadão na escolha das suas alternativas e na decisão sobre seu destino" (BUARQUE, 1999, p. 26).

Pelas características descritas, percebe-se que o projeto da Itaipu foi implantado de forma verticalizada, de cima para baixo; seu argumento convence as lideranças e aparece como uma boa propaganda ${ }^{5}$, entretanto apresenta muitos lapsos no campo prático.

Deixa-se claro que não se desconsidera a importância das iniciativas realizadas na comunidade, porém percebe-se que se passaram 12 anos do início do Projeto da Itaipu e os indígenas não conseguiram sua autonomia para geração de alimentos e renda, mantendo

\footnotetext{
${ }^{5}$ Recebeu o segundo lugar geral no Ranking Benchmarking 2013
} 
dependência dos incentivos realizados pela empresa.

Percebe-se que as ações realizadas, apesar de apelarem para o termo "sustentabilidade", não correspondem à compreensão básica de sustentabilidade como harmonia entre as dimensões econômicas, ambientais e sociais ao longo do tempo, assim como proposto pelo Relatório Brundtland "Nosso Futuro Comum" (1991), compartilhado pela Itaipu. Muito menos corresponde a outras concepções mais integradoras e sistematizadas de desenvolvimento sustentável.

Além dos motivos já apontados, entende-se que as ações não podem ser consideradas sustentáveis, uma vez que, no máximo, suprem necessidades imediatas, como também não estão sendo respeitadas as capacidades de regeneração, reprodução e coevolução dos bens e serviços naturais (BOFF, 2015, p. 107) devido ao ínfimo território e a adoção de práticas incompatíveis com a harmonia do meio ambiente, produção e cultura, como também não suprem as necessidades das gerações atuais, além de prejudicar as possibilidades das futuras gerações.

Percebe-se que, da maneira que está sendo realizado o Projeto Sustentabilidade das Comunidades Indígenas, não há preocupação com a sustentabilidade como proposta na teoria, mas sim apenas com números, tornando-a uma grande ação de marketing.

\section{A implantação do Projeto GATI na Terra Indígena do Oco’y}

A promulgação da Política Nacional de Gestão Ambiental e Territorial de Terras Indígenas (PNGATI), através do Decreto 7.747/2012, é um marco importante na luta dos povos indígenas por uma política pública indigenista abrangente, que envolvesse proteção territorial, conservação ambiental e a sustentabilidade das ações em territórios indígenas.

A PNGATI impulsiona as ações de gestão territorial de terras indígenas, pois cria meios legais para a gestão e o desenvolvimento se materializar, agregando diferentes atores e instituições, direcionando verbas, servindo como diretriz para realização de projetos que prezam pela sustentabilidade ambiental, econômica e social, respeitando a 
autonomia e promovendo a participação da sociedade indígena (FUNDAÇÃO NACIONAL DO ÍNDIO, 2012).

O Projeto de Gestão Ambiental e Territorial em Terras Indígenas (GATI) é uma das formas de realização das diretrizes impostas pelo PNGATI e possui o objetivo de construir um desenvolvimento voltado à qualidade de vida das comunidades, com o auxílio de diversos órgãos governamentais, instituições e, sobretudo, dos próprios indivíduos envolvidos.

Fazem parte do Projeto organizações indígenas, a Fundação Nacional do Índio (Funai), o Ministério do Meio Ambiente (MMA), The Nature Conservancy (TNC), o Programa das Nações Unidas para o Desenvolvimento (PNUD) e o Fundo Mundial para o Meio Ambiente (GEFGlobal Environment Facility).

Foram selecionadas 32 terras indígenas nos cinco biomas florestais brasileiros, seguindo alguns critérios. Três destes partem da constatação de um protagonismo indígena existente no território; um trata da relevância da fauna e flora; e outro, em função de possíveis empecilhos que não atrapalhem as ações do projeto e possam ser minimizados pela atuação do projeto (IMPLEMENTAÇÃO, 2015).

O GATI iniciou suas atividades a partir da consulta local, obedecendo às diretrizes impostas pela PNGATI, realizando a primeira reunião em outubro de 2012, com o intuito de definir alguns objetivos. Contou com participação de lideranças indígenas, servidores da Funai, representantes de órgãos parceiros e do Programa das Nações Unidas para o Desenvolvimento. Foram três dias de debates, com o objetivo de organizar a gestão do Projeto no que resultou na construção do Conselho Regional Deliberativo do Núcleo Regional Sul do Projeto GATI. E, por fim, organizados em grupos por áreas de referência, lideranças indígenas e representantes dos órgãos debateram sobre os Planos de Ação que deveriam ser estabelecidos em cada uma das TIs (VILLANUEVA, 2012).

As atividades práticas foram iniciadas na comunidade em 2013, com ações focadas na necessidade de otimização do território indígena para a produção de alimentos e renda. Realizaram-se "iniciativas que integram o uso sustentável do solo, a produção de alimentos de qualidade, o resgate e valorização de espécies tradicionais, a segurança alimentar e a comercialização dos excedentes". Nessa etapa, o projeto 
contou com o apoio da Associação dos Produtores e Pecuária Orgânica de São Miguel do Iguaçu e da Prefeitura Municipal de São Miguel do Iguaçu (GATI, 2014).

A cooperação entre organizações, do nível global ao local, é fundamental para a realização do desenvolvimento sustentável, uma vez que, com a descentralização político-administrativa do Estado brasileiro e com a influência do processo de globalização, diferentes atores de diferentes escalas agem sobre o território, algumas vezes de maneira conflituosa e outras em sinergia (RAMBO e RUCKERT, 2008). Dessa forma, é interessante notar como estão articulados em diferentes escalas os atores que promovem a sustentabilidade em determinadas etapas do processo de desenvolvimento. Isto é possível pois as parcerias estão previstas pelo Art. $3^{\circ}$ Inciso XIII da PNGATI, como forma de compatibilizar iniciativas de diferentes escalas.

A estratégia iniciada pelo Projeto é a do aproveitamento do pouco território para gerar alimentos diversificados e saudáveis. Assim, foram desenvolvidos alguns microprojetos: "Apoio à implantação de pomar agroflorestal", "Agrofloresta para segurança alimentar e recuperação de áreas degradadas", "Implantação de quintais agroflorestais" e "Hortas de Mandala". Também foram realizadas oficinas, palestras e intercâmbios visando a troca de experiências de manejo e de caminhos a seguir para produzir e gerar renda (GATI, 2014).

A opção por atividades agroecológicas se apresenta como estratégia adequada de produção sustentável para a Terra Indígena Oco'y, pois busca diversidade e aumento de produção de alimentos no pouco território disponível, além de estimular a relação da diversidade produtiva com característica de manejo consorciado do Avá-Guarani.

Segundo Candiotto, Carrijo e Oliveira (2008), a agroecologia e os sistemas agroflorestais

se apresentam como atividades integradas que buscam unir e equilibrar interesses de conservação ambiental; qualidade dos alimentos; segurança alimentar das famílias agrícolas e da sociedade; manutenção dos agricultores familiares no campo; resgate e valorização sociocultural; e retorno econômico para as famílias rurais (CANDIOTTO, CARRIJO e OLIVEIRA, 2008, p. 214). 
Sugere-se que os indígenas sejam estimulados a resgatar os seus conhecimentos tradicionais aliados aos conhecimentos da agricultura sustentável, principalmente a partir da agroecologia e sistemas agroflorestais, uma vez que estes são consoantes com os interesses indígenas.

Sobre a relação entre conhecimentos tradicionais e técnicas da ciência ocidental, Smith e Guimarães (2010) afirmam:

O diálogo entre diferentes formas de conhecimentos, sobretudo de conhecimentos indígenas locais e de conhecimentos acumulados nos moldes da ciência ocidental é um aspecto desejável para melhorar a efetividade de ações de gestão ambiental nas terras indígenas. No entanto, é importante considerar nesse processo de diálogo, que a base de construção de estratégias de gestão deve privilegiar os conhecimentos locais e que, conhecimentos externos (como aqueles propostos pela ciência ocidental ou outros atores) sejam, antes de tudo, apropriados pelos povos indígenas de acordo com sua lógica e racionalidade específicas (SMITH e GUIMARÃES, 2010, p, 11).

A agroecologia é um meio de produção que se opõe ao modelo agrícola convencional hegemônico na sociedade não indígena e presente na TI Oco'y por incentivo da Itaipu. Este modelo alternativo valoriza e "incorpora, aos objetivos de conservação ambiental presentes na agricultura orgânica, objetivos sociais, onde agricultores e consumidores devem ser valorizados e beneficiados no processo" (CANDIOTTO, CARRIJO e OLIVEIRA, 2008, p. 222).

Por se tratar de uma Área de Preservação Permanente, a implantação de pomares e quintais agroflorestais constitui-se de uma iniciativa que promoverá a alimentação em curto e médio prazo, como também o reflorestamento da margem do lago. Por fim, as hortas de mandala são pequenas intervenções no território que também promovem diversidade de cultivares e podem ser instaladas utilizando pouco espaço.

No documento "Síntese da reunião de instalação do Conselho Regional do Núcleo Regional Sul do Projeto GATI" (VILLANUEVA, 2012), foram definidas algumas atividades que deveriam ser implementadas no futuro e serão comentadas a seguir:

São elas: 1) Etnomapeamento com enfoque em identificação da 
biodiversidade de valor cultural e de áreas de invasão; 2) Cercamento das áreas de invasão; Formação e capacitação de jovens indígenas para atuação como Agentes Ambientais; 3) Revitalização de trilhas e construção de centro de lazer e visitação; 4) Fortalecimento de Redes de experiências com outras aldeias guarani, inclusive no Paraguai, com enfoque na agrobiodiversidade guarani; 5) Criação de um banco de sementes tradicionais guarani; 6) Pomar na área da escola e quintais agroflorestais; 6) Diagnóstico da agrobiodiversidade local (VILLANUEVA, 2012).

O Etnomapeamento é uma ferramenta com certa tradição para o planejamento da gestão ambiental e territorial de terras indígenas e está prevista na PNGATI. É definida como o "mapeamento participativo das áreas de relevância ambiental, sociocultural e produtiva para os povos indígenas, com base nos conhecimentos e saberes indígenas" (BRASIL, 2012, n.p.).

Através da construção do Etnomapeamento, é possível conceber um material com múltiplas finalidades, como a identificação de potencialidades e fragilidades dos recursos existentes na terra indígena, levantamento de dados sociais, econômicos, culturais, ambientais, sanitários, patrimoniais, entre outros (REDE DE COOPERAÇÃO ALTERNATIVA, 2013). A realização do Etnomapeamento, na perspectiva deste trabalho, deve ser a primeira ação realizada após a criação dos núcleos de gestão, uma vez que levantará importantes dados para repensar o planejamento das ações.

A construção de cercas é necessária, pois o desrespeito aos limites das terras indígenas é um problema comum a diversos povos; no caso da TI Oco'y, segundo Carvalho (2013), a área invadida por agricultores vizinhos chega a 4,9 hectares. É um problema antigo que deveria ser resolvido pela Funai, uma vez que esta tem competência de polícia. Diante da inércia do órgão, se faz necessária uma ação de cercamento, como forma de imposição dos limites e dos direitos da Terra Indígena, que precisam se fazer valer.

Também é necessário trabalhar a conscientização dos agricultores vizinhos que, a partir da atuação em suas terras, impactam no território do Oco'y. Invadindo pouco a pouco o território indígena, intoxicam indiretamente a comunidade indígena pelos agrotóxicos utilizados nas 
plantações.

A realização de redes de experiência e intercâmbios culturais é uma ação que apresenta diversos resultados positivos nas terras indígenas do norte do país. Através dos encontros realizados, indígenas de diferentes terras indígenas têm a oportunidade de conhecer a realidade de outras terras indígenas com contexto variados. Nestas visitas, os próprios indígenas trocam informações, destacam pontos positivos e negativos que encontram na terra indígena em que visitam, comparam os contextos em que vivem com o que visitam, discutem e articulam interesses, fortalecem laços, produzem documentos, entre outras ações (RCA, 2013).

Acredita-se que a realização de uma rede de experiência, de certa forma, será um direcionamento das atividades já realizadas através da mobilidade característica dos guarani ${ }^{6}$, que já possuem uma grande rede de contato na região (ALBERNAZ, 2007). É possível se espelhar nas experiências existentes em outros locais e permitir que os indígenas reflitam e discutam temas de interesse comum, fortalecendo a relação entre os indígenas e permitindo o seu protagonismo.

Até então pode-se rastrear através do site voltado ao projeto ${ }^{7}$ que foram realizadas e estão sendo privilegiadas atividades visando à formação indígena, bem como oficinas sobre princípios de agroflorestas, apoio a hortas agroecológicas e quintais agroflorestais, porém não foram encontrados registros noticiados da construção do Etnomapeamento do território, nem do início das atividades de redes de experiência.

Também foi disponibilizado um edital no valor de 40 mil reais para a realização de oficinas, cursos e atividades práticas de manejo e recuperação de áreas degradas, entre outros. Entretanto, no resultado final, nenhum projeto foi proposto para o Oco'y ${ }^{8}$.

\footnotetext{
${ }^{6}$ Sobre a tradição da mobilidade guarani, conferir Silva (2007).

${ }^{7}$ http://cggamgati.funai.gov.br.

8 O resultado pode ser conferido neste link: http://cggamgati.funai.gov.br/index.php/projetogati/noticias/ispn-e-projeto-gati-divulgam-lista-de-projetos-aprovados-no-edital-ppp-gati/ .
} 


\section{Considerações Finais}

O Projeto GATI é, sobretudo, um desafio a ser superado pelos indígenas e pelo poder público, pois baseia-se em uma política nacional que busca atender mais de 500 terras indígenas. Assim, cada nova ação a ser implementada encontrará um contexto diferente e, por isso, deverá ser planejada considerando aspectos sociais, econômicos, culturais, territoriais, ambientais, entre outros, específicos de cada terra indígena.

Um dos critérios para a seleção de terras indígenas participantes é a existência de alguma iniciativa de gestão de recursos naturais, para que o GATI tenha uma base para apoiar suas ações. No presente caso estudado, a existência de uma experiência de gestão realizada pela Itaipu é uma oportunidade de refletir e melhorar as ações para que a nova iniciativa não repita os mesmos erros da primeira.

Através da comparação com o projeto desenvolvido pela Itaipu e o projeto GATI é possível perceber que ambos possuem objetivos semelhantes, ou seja, suprir as necessidades indígenas de forma sustentável; entretanto, seguem valores e premissas diferentes, que condicionam resultados diferentes.

A Itaipu realiza uma abordagem imediatista de apelo à sustentabilidade, buscando saciar as necessidades urgentes da comunidade. Embora venha desempenhando importante papel na alimentação e promoção de atividades culturais e econômicas na Terra Indígena, não contribuiu para a autonomia dos indígenas de forma que deixassem de depender da instituição incentivadora, o que não é o esperado de um projeto de desenvolvimento sustentável, não condizendo com o debate teórico que afirma a necessidade de uma abordagem integrada de diferentes dimensões.

Por sua vez, o GATI possui uma abordagem sustentável, isto é, preocupa-se com a satisfação das necessidades atuais e futuras, buscando harmonizar o desenvolvimento ambiental, econômico, social e cultural. A partir da base teórica aqui utilizada, isso indica que está trilhando os caminhos adequados ao seu objetivo de desenvolver a sustentabilidade através da gestão ambiental e territorial.

As ações realizadas até então pelo Projeto GATI condizem em maior ou menor grau com as 13 diretrizes do PNGATI. Destas, podem ser 
retirados os incisos $\mathrm{VI}$ e VII, por não se tratarem do contexto da Terra Indígena Oco'y. As outras diretrizes se complementam ao falar da importância da gestão ambiental, a necessidade da proteção territorial, autonomia, direito a consulta prévia e parcerias institucionais, como ditos anteriormente. Somente sobre a diretriz exposta no Inciso IV, sobre o reconhecimento e valorização das mulheres indígenas, não foram constatadas maiores ações além da participação de uma mulher na reunião de instalação do Conselho Regional.

Com a criação do PNGATI, uma política construída por indígenas e órgãos indigenistas, poderia se esperar que a Itaipu, uma empresa binacional, considerasse a nova política e revisse suas ações, realizando uma transformação estrutural em seu projeto, o que parece não ter previsão de ocorrer. Como também é possível que as duas iniciativas se integrem, uma vez que ambas têm bases legais para tal e objetivos semelhantes.

\section{Referências bibliográficas}

ALBERNAZ, Adriana R. Interpretações de mundo e projetos de futuro dos Avá-Guarani do Oco'y. Espaço Ameríndio, Porto Alegre, v. 1, n. 1, p. 146 - 169, 2007.

O Provisório em Definitivo: a organização social dos Ava-Guarani da área indígena de Oco'y (PR). Tellus, Campo Grande, v. 8, n. 14, p. 115-144, 2008. Disponível em: www.tellus.ucdb.br/index.php/tellus/article/view/153. Acesso em: jul. 2015.

BOFF, Leonardo. Sustentabilidade: o que é - o que não é. Petrópolis: Vozes, 2015.

BRASIL. Decreto 7.747, de 5 de junho de 2012. Disponível em: http://www.planalto.gov.br/ccivil_03/_ato2011-2014/2012/decreto/d7747.htm . Acesso em: jul. 2015.

BRIGHENTI, Clovis Antonio. Necessidade de novos paradigmas ambientais: implicações e contribuição Guarani. In: Cadernos PROLAM/USP, São Paulo, v. 2, n. 4, p. 33-56, 2005.

BUARQUE, Sérgio C. Metodologia de planejamento do desenvolvimento local e municipal sustentável: Material para orientação técnica e treinamento de multiplicadores e técnicos em planejamento local e municipal. Brasília, 1999. 104 p. 
CANDIOTTO, Luciano Z. P.; CARRIJO; Beatriz R.; OLIVEIRA, Jackson A. A Agroecologia e as Agroflorestas no contexto de uma Agricultura Sustentável. In: ALVES, Adilson F.; CARRIJO, Beatriz R.; CANDIOTTO, Luciano Z. P. (Org.). Desenvolvimento territorial e agroecologia. São Paulo: Expressão Popular, 2008. p. 213-232.

CARIBÉ, Karla Virgínia Bezerra. Área de Preservação Permanente: APP em Reservatórios d'água artificiais após o Novo Código Florestal (Lei $n^{\circ}$ 12.651/2012). Âmbito Jurídico, Rio Grande, v. 16, n. 116, 2013. Disponível em: http://www.ambitojuridico.com.br/site/?n_link=revista_artigos_leitura\&artigo_id=13671. Acesso em: jul 2015.

CARVALHO, Maria Lúcia Brant. Das terras dos índios aos índios sem terra: o Estado e os Guarani do Oco'y - Violência, Silêncio e Luta. 2013. 834 f. Tese (Doutorado em Geografia) - Universidade de São Paulo, [2013].

DEPRÁ, Giseli. O lago de Itaipu e a luta dos Avá-Guarani pela terra: representações na imprensa do Oeste do Paraná (1976-2000). 2006. 136 f. Dissertação (Mestrado em História) - Universidade Federal da Grande Dourados, Dourados, [2006].

FREY, Klaus. Capital social, comunidade e democracia. Política \& Sociedade, Florianópolis, n. 2, p. 175-187, 2003. Disponível em: https://periodicos.ufsc.br/index.php/politica/article/view/4958>. Acesso em: Jul. 2015.

FUNDAÇÃO NACIONAL DO ÍNDIO. Programa de Proteção e Promoção dos Direitos dos Povos Indígenas: Plano Plurianual 2012-2015. Brasília: Funai, 2012.

GATI. Projeto GATI promove apoio a quintais agroflorestais e hortas agroecológicas na TI Ava-Guarani de Oco'y (PR). 2015. Disponível em: http://cggamgati.funai.gov.br/index.php/projeto-gati/noticias/projeto-gati-promoveapoio-quintais-agroflorestais-e-hortas-agroecologicas-na-ti-ava-guarani-de-ocoy-pr/. Acesso em: jul. 2015.

IBGE. Os indígenas no Censo Demográfico 2010: primeiras considerações com base no quesito cor ou raça. Rio de Janeiro, 2012.

IMPLEMENTAÇÃO. Como está sendo a implementação do Projeto GATI. 2015. Disponível em: http://cggamgati.funai.gov.br/index.php/projeto-gati/o-que-e-ogati/implementacao/. Acesso em: jul. 2015.

JORNAL do programa socioambiental da Itaipu Binacional. Cultivando Água Boa. Foz do Iguaçu, n. 24, nov. 2013

NIMUENDAJU, Curt Unkel. As lendas da criação e destruição do mundo: como fundamento da religião dos Apapocuva-Guarani. São Paulo: Hucitec-Edusp, 1987.

O QUE É O PROJETO GATI? Conheça o seu objetivo e parcerias. Disponível em: http://cggamgati.funai.gov.br/index.php/projeto-gati/o-que-e-o-gati/. Acesso em: jul. 
2015.

ORSI, Magali Rosângela S. A Atividade Piscícola em Tanques-Rede no Reservatório de Itaipu: o caso da Comunidade Indígena Tekoha Ocoy. 2011. 51 f. Dissertação (Mestrado em Recursos Pesqueiros e Engenharia de Pesca) - UNIOESTE, Toledo, [2011].

RAMBO, Anelise G.; RUCKERT, Aldomar A. Desenvolvimento territorial e escalas geográficas de poder e gestão - o caso da Cooperacana, Porto Xavier-RS. Geosul, Florianópolis, v. 23, n. 46, p. 95-114, 2008. Disponível em: http://unbral.nuvem.ufrgs.br/base/files/original/2a13f051c2252c38a78f4c195825dd44.p df. Acesso em: jul.2015.

REDE DE COOPERAÇÃO ALTERNATIVA - RCA, Gestão territorial e ambiental em terras indígenas na Amazônia brasileira: os percursos da Rede de Cooperação Alternativa. São Paulo, 2013.

RELATÓRIO anual. Programa 400 - Sustentabilidade de segmentos vulneráveis, Ação 2269: Sustentabilidade de Comunidades Indígenas. 2014. Disponível em: http://apublica.org/wp-content/uploads/2015/03/9-Relat\%C3\%B3rio-Anual-de-Itaipude-Sustentabilidade-com-Ind\%C3\%ADgenas-2014.doc.pdf. Acesso em: jul. 2015.

RIBEIRO, Sarah I. G. T. Fronteira e Espacialidade: o caso dos guarani no oeste do Paraná. Revista Varia Scientia, Maringá, v. 6, n. 12, p. 171-192, 2006.

SACHS, Ignacy. Caminhos para o Desenvolvimento Sustentável. Rio de Janeiro: Garamond, 2002.

SILVA, Evaldo Mendes. Folhas ao vento: a micromobilidade de grupos Mbya e Nhandéva (Guarani) na Tríplice Fronteira. 2007. 265 f. Tese (Doutorado em Antropologia) - Museu Nacional: Rio de Janeiro, [2007].

SMITH, Maíra; GUIMARÃES, Marco Aurélio. Gestão Ambiental e Territorial de Terras Indígenas: Reflexões sobre a construção de uma nova política indigenista. In: V Encontro da Associação Nacional de Pós-Graduação e Pesquisa em Ambiente e Sociedade. Anais... Florianópolis. $2010 . \quad$ Disponível em: http://www.anppas.org.br/encontro5/cd/artigos/GT3-82-440-20100903170251.pdf.

Acesso em: jul. 2015.

VILLANUEVA, Rosa E. Síntese da reunião de instalação do Conselho Regional do Núcleo Regional Sul do Projeto GATI. Nov. 2012.

Recebido em: 02/09/2015 * Aprovado em: 08/11/2015 * Publicado em: 31/12/2015

DIAS, Roberto dos Anjos; SILVA, Nardel Luiz Soares. As diferenças nas ações do projeto de sustentabilidade das comunidades indígenas (Itaipu) e do Projeto Gati na Terra Indígena do Oco'y - PR. Espaço Ameríndio, Porto Alegre, v. 9, n. 3, p. 109-130, jul./dez. 2015. 